Anton Friedrich Koch

\title{
Die Evolution des logischen Raumes
}

\author{
Aufsätze zu Hegels Nichtstandard-Metaphysik
}

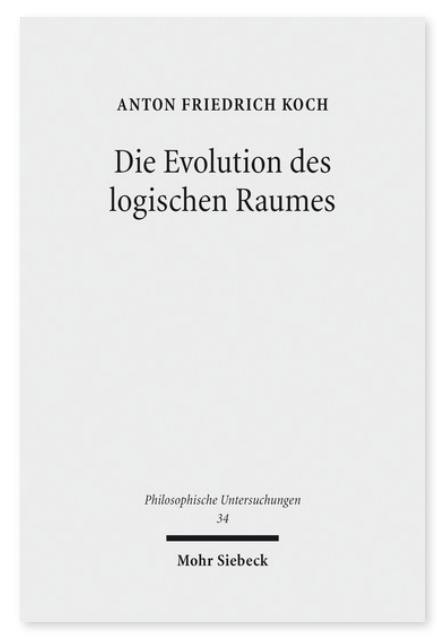

2014. VIII, 327 Seiten. PhU 34

ISBN 978-3-16-153096-8

DOI 10.1628/978-3-16-153096-8

eBook PDF $69,00 €$

ISBN 978-3-16-153011-1

fadengeheftete Broschur 69,00€
Der Schwerpunkt dieses Werkes, einer Aufsatzsammlung, liegt auf der theoretischen Philosophie Hegels, einerseits auf der Methode und den Anfangskapiteln der Phänomenologie des Geistes, andererseits auf der Wissenschaft der Logik. Anton Friedrich Kochs Hauptanliegen ist es zu zeigen, daß Hegel im Einvernehmen mit der Skepsis, d. h. ohne metaphysische Prämissen philosophiert. Insbesondere wird die Wissenschaft der Logik als der Versuch einer voraussetzungslosen Theorie präsentiert und auf dieser Basis in ihren zentralen Lehren rational rekonstruiert. Wenn man unter dem logischen Raum die Gesamtheit dessen versteht, was der Fall sein und gedacht werden kann, wird man die Metaphysik als die Theorie des logischen Raumes betrachten dürfen. Das Alleinstellungsmerkmal der Hegelschen Logik ist es nun, daß sie den logischen Raum nicht als unwandelbare Gegebenheit, sondern als einen prätemporalen, logischen Prozeß faßt, in dessen Verlauf die begrifflichen Kernbestimmungen aller möglichen metaphysischen Theorien ihre Auftritte haben, sich dabei als inkohärent erweisen und jeweils von Nachfolgerbestimmungen abgelöst werden, die ebenfalls inkohärent sind. Am Ende bleibt keine siegreiche Einzelbestimmung als Kern einer neuen Standard-Metaphysik übrig, sondern eine methodische Reflexion auf den logischen Prozeß insgesamt. So ist Hegels Logik als Evolutionstheorie des logischen Raumes zugleich eine Kritik jeder möglichen Standard-Metaphysik, versteht sich aber selbst noch als streng theoretische, nicht-hermeneutische Wissenschaft und insofern noch als Metaphysik, wenn auch als Nichtstandard-Metaphysik.

Anton Friedrich Koch Geboren 1952 in Gießen; Studium der Philosophie und Germanistik; 1980 Promotion in Heidelberg; 1989 Habilitation in München; 1993-96 Professor für Geschichte der Philosophie in Halle; 1996-2009 Professor für Philosophie in Tübingen; seit 2008 Mitglied der Heidelberger Akademie der Wissenschaften; seit 2009 Professor für Philosophie an der Universität Heidelberg.

Jetzt bestellen:

https://mohrsiebeck.com/buch/die-evolution-des-logischen-raumes-9783161530968?no_cache=1

order@mohrsiebeck.com

Telefon: +49 (0)7071-923-17

Telefax: $+49(0) 7071-51104$ 